\title{
Comparison between tuberculin test results and ELISA for diagnosis of bovine tuberculosis
}

\author{
F. R. El-Seedy ${ }^{1}$, Sohair S. Elyas ${ }^{2}$, W. H. Hassan ${ }^{1 *}$, E. A. Nasr ${ }^{3}$ \\ ${ }^{1}$ Department of Bacteriology Mycology and Immunology, Faculty of Veterinary Medicine, Beni-Suef University, Egypt \\ ${ }^{2}$ Animal Health Research Institute Dokki, Gizza, Egypt \\ ${ }^{3}$ Veterinary Serum and Vaccine Research Institute Abbassia, Cairo, Egypt
}

\begin{abstract}
A total of 300 cross-bred dairy cattle in Beni-Suef and El-Fayoum Governorates were screened for bovine tuberculosis using single intradermal (SID) cervical tuberculin test. 18 out of $300(6 \%)$ tested cattle were found tuberculin positive. Blood samples from the positive reactors were tested by ELISA. ELISA plates were coated by either bovine purified protein derivative (PPD) or short term culture filtrate (ST-CF) antigens. The test sensitivity was compared at different serum dilutions. At serum dilution of 1/40, all of the 18 tuberculin positive samples, $(100 \%)$, were ELISA positive using both ST-CF and PPD antigens, but at 1/80 dilution, $13(72.22 \%)$ and $12(66.66 \%)$ samples; at 1/160, $11(61.11 \%)$ and $11(61.11 \%)$ and finally at 1/320, $10(55.55 \%)$ and $9(50 \%)$ were ELISA positive on using ST-CF and PPD as a coating antigens respectively.
\end{abstract}

Tuberculosis in cattle caused by Mycobacterium bovis (M. bovis) continues to be a problem both in countries with and without active control policies (Thom et al., 2006). Bovine tuberculosis was responsible for approximately $6 \%$ of total human tuberculosis deaths in 1930-1940 (Vordermeier et al., 2001). Bovine tuberculosis (TB) is characterized by the progressive development of granulomatous lesions in different body organs and can affect a large number of species. The incidence of bovine TB is rising, both in the number of herds affected and in the number of cases per affected herd (Cobner, 2003). It affected over 50 million cattle world-wide resulting in economic losses of approximately 3 billion \$ (Hewinson, 2000).

The intradermal tuberculin test is the only prescribed test for the diagnosis of tuberculosis in cattle (Cousins and Florisson, 2005). The purified protein derivative (PPD) is still the most widely used antigen, however, it contains many antigenic determinants of broad specificity that lead to the appearance of non-specific reactors; animals react positively to tuberculin test but not actually infected, also false negative reactors which give negative tuberculin test although animals are actually tuberculous (Radostits et al., 2000). Therefore, alternate more specific

\footnotetext{
* Corresponding author. Tel.: +2 0101546485; fax: +20822327982 .

E-mail address: dr_walidh@yahoo.com (W. H. Hamdy).
}

immunodiagnostic methods are needed. Development of an accurate serodiagnostic test requires detailed understanding of humoral immune response during bovine tuberculosis as well as identification of the key antigens of $M$. bovis involved in antibody production (Lyaschchenko et al., 1998).

The present study was conducted to demonstrate the relationship between the results of tuberculin test and ELISA results using either PPD or ST$\mathrm{CT}$ as coating antigens.

\section{Materials and Methods}

Animals. A total of 300 cross-bred dairy cattle in Beni-Suef and El-Fayoum Governorates were tested by single intradermal (SID) cervical tuberculin test, blood samples were collected from the positive reactors animals before slaughtering.

Tuberculin test. A narrow zone at the middle third of the neck of the tested animals was marked by clipping the hair. The skin thickness was measured by using the caliber then $0.1 \mathrm{ml}$ of human tuberculin was injected intradermaly. The skin thickness was measured $72 \mathrm{~h}$. post injection and the differences in skin thickness were recorded in millimeters. According to the general organization of veterinary services (GOVS), an increase in the skin thickness of 4 $\mathrm{mm}$ or more was considered positive, less than 3 $\mathrm{mm}$ was considered as negative and from $3-4$ as doubtful.

Antigens. 
Bovine PPD antigen (trichioroacetic acid precipitated: TCA-PPD). It was kindly obtained from bacterial diagnostic products department of veterinary serum and vaccine research institute (VSVRI), Cairo, Egypt.

Preparation of short term culture filtrate (STCF) of M. bovis. It was conducted according to Andersen et al. (1991) and Gupta et al. (1998). M. bovis AN5 was kindly obtained from VSVRI, Abbassia Cairo, Egypt and cultured in Middlebrook $7 \mathrm{H} 9$ broth at $37^{\circ} \mathrm{C}$ for 2 weeks. Culture filtrate was obtained form 2weeks aged cultures. It was harvested by filtration using $0.22 \mu \mathrm{m}$ disposable filler units to remove any bacterial cells. Phenyl methyl sulphonyl fluoride (PMSF) was added at $1.0 \mathrm{mM}$ final concentration. Culture filtrate was dispensed in $10 \mathrm{ml}$ capacity vials, each vial contained $2 \mathrm{ml}$ and subjected to lyophilization using Labconco freeze dryer $-47^{\circ} \mathrm{C}, 37 \times 10^{3} \mathrm{~mm}$ $\mathrm{Hg}$ pressure till complete dryness of culture filtrate, according to the manufacture's instructions and stored at $4{ }^{\circ} \mathrm{C}$ till used. The short term culture filtrate of $M$. bovis was reconstituted with PBS (pH 7.4) then PMSF $1 \mathrm{mM}$ was added and kept frozen at $-20^{\circ} \mathrm{C}$. Estimation of total protein concentration of ST-CF was performed according to (Lawry et al., 1951). Briefly, $0.2 \mathrm{ml}$ of standard protein (bovine serum albumin; BSA; ICN biomedical Inc.), mycobacterial antigen (ST-CF) and standard control were pipetted out in test tubes and $2 \mathrm{ml}$ of analytic reagent were added. The solution was mixed well and incubated at room temperature for $10 \mathrm{~min} .0 .2 \mathrm{ml}$ of folin-ciocalteous $(1 \mathrm{~N})$ reagent was added to the tube and incubated at room temperature for $30 \mathrm{~min}$. Optical density was recorded at $660 \mathrm{~nm}$. Standard calibration curve was made by blotting the absorbance of standard against concentration. The concentration of total protein of ST-CF sample was estimated.

Standardization of the ST-CF antigen. Before using mycobacterial ST-CF antigen used as ELISA coating antigen, it was screened for its sterility, solubility and antigenicity.

a. Sterility test. $0.1 \mathrm{ml}$ of the M. bovis (SI- CF) was diluted 1:100 in sterile distilled water; 0.1 $\mathrm{ml}$ was inoculated into nutrient broth and thioglycollate medium for examining the growth of any both aerobic and anaerobic bacteria. Bacto-Sabouraud maltose agar medium was also used for screening fungal growth where incubation was at $25^{\circ} \mathrm{C}$ for 7 days. Modified
Lowenstein Jensen medium slopes in MacCartney bottles were used to confirm the absence of viable $M$. bovis where incubation was performed at $37{ }^{\circ} \mathrm{C}$ for $6-8$ weeks according to (Gupta and Ram, 2000).

b. Solubility test. The prepared ST-CF of $M$. bovis was fairly soluble in PBS (pH 7.4) containing $10 \mathrm{mM}$ (PMSF).

c. Antigenicity. M.bovis ST-CF was screened for its ability to induce delayed type hypersensitivity by the intradermal injection of $M$. bovis sensitized guinea pigs (Heilman, 1967).

Enzyme linked immunosorbent assay (ELISA) using bovine PPD and ST-CF as coating antigens. ELISA was performed as described previously (Hall and Thoen, 1985; Dimitri et al., 1990). Briefly, $100 \mu 1$ of either PPD or ST-CF antigens diluted in carbonate bicarbonate buffer saline: $\mathrm{pH}$ : $9.6(15 \mu \mathrm{g} / \mathrm{ml})$ were used to coat wells of ELISA plates. Each well then received $50 \mu \mathrm{l}$ carbodiimide in $0.1 \mathrm{M}$ sod. Carbonate buffer, incubated at $4^{\circ} \mathrm{C}$ over night, washed 3 times in PBS, air dried, incubated in $22^{\circ} \mathrm{C}$ with $0.01 \mathrm{M}$ ammonium chloride $(100 \mu 1 /$ well $)$ for 30 min. After three washes with PBS, the wells were blocked with $1 \%$ ova albumen in PBS for 1 $\mathrm{h}$ at room temperature. $100 \mu \mathrm{l}$ of different dilutions of each serum sample (tuberculin positive) was added per well $(1 / 40,1 / 80,1 / 160$ and $1 / 320$ in phosphate-buffered saline [PBS]Tween 20) for either PPD or ST-CF. The antigen-antibody binding was allowed to proceed for $60 \mathrm{~min}$. at room temperature and $100 \mu 1$ of alkaline phosphatase-conjugated rabbit anti-bovine IgG diluted 1:5000 in PBS-Tween 20, was added per well. After $60 \mathrm{~min}$ the plates were washed three times then p-nitrophenyl phosphate $(100 \mu \mathrm{l} /$ well $)$ was added and incubated for $15 \mathrm{~min}$. The optical density was measured at $405 \mathrm{~nm}$ after stopping the reaction by $\mathrm{NaOH}$ to a final concentration of $1 \mathrm{M}(50 \mu \mathrm{l}$ /well).

\section{Results}

Tuberculin test. $18(6.0 \%)$ out of the 300 tested cattle, were found to be tuberculin test positive (the increase in skin thickness $\geq 4 \mathrm{~mm}$ ).

Bovine ST-CF antigen preparation. M. bovis AN5 strain was grown well on Middlebrook 7H9 broth medium. The convoluted pellicle was intact until the end of the growth period. Colour of short term culture filtrate antigen in lyophilized form was whitish beige and in solution form was dark yellow. The results of purity test confirmed that ST-CF antigen was 
Table (1): ELISA results of cattle serum samples (positive tuberculin) using bovine PPD and ST-CF as coating antigens.

\begin{tabular}{ccccccccccc}
\hline \multirow{2}{*}{$\begin{array}{c}\text { Sample } \\
\text { No. }\end{array}$} & Tuberculin & \multicolumn{9}{c}{ PPD } \\
\cline { 2 - 10 } & test & $1 / 40$ & $1 / 80$ & $1 / 160$ & $1 / 320$ & $1 / 40$ & $1 / 80$ & $1 / 160$ & $1 / 320$ \\
\hline 1 & + & + & + & + & - & + & + & + & - \\
2 & + & + & + & + & + & + & + & + & + \\
3 & + & + & + & + & + & + & + & + & + \\
4 & + & + & + & + & + & + & + & + & + \\
5 & + & + & + & + & - & + & + & + & + \\
6 & + & + & - & - & + & + & + & - & + \\
7 & + & + & + & + & - & + & + & + & - \\
8 & + & + & + & + & + & + & + & + & + \\
9 & + & + & - & - & + & + & + & - & + \\
10 & + & + & + & + & - & + & - & + & - \\
11 & + & + & - & - & - & + & + & + & + \\
12 & + & + & + & + & + & + & + & + & + \\
13 & + & + & + & - & - & + & + & - & - \\
14 & + & + & + & + & + & + & + & + & + \\
15 & + & + & + & + & + & + & - & - & - \\
16 & + & + & - & - & - & + & - & - & - \\
17 & + & + & - & - & - & + & - & - & - \\
18 & + & + & - & - & - & + & - & - & - \\
\hline
\end{tabular}

The serum dilution was considered positive if OD equal or more than the cut-off value.

The cut of value $=$ mean optical density of negative control plus 2 standard deviation (Nassau et al., 1976)

The cattle considered ELISA positive if serum dilution 1/80 or more give positive results (Narayanan et al., 1983)

No. $=$ Number $+=$ positive $-=$ negative

free from any bacterial or fungal contamination. Also it was biologically active product and it was able to induce delayed type hypersensitivity (DTH) by the intradermal injection of $M$. bovis sensitized guinea pigs. The concentration of protein of M. bovis ST-CF was $2.7 \mathrm{mg} / \mathrm{ml}$ in the second week of growth.

ELISA. All serum samples, 18, (100\%) at 1/40 dilution were ELISA positive using both PPD and ST-CF antigens. At serum dilution 1/80, 13 samples $(72.22 \%)$ were positive using ST-CF meanwhile, 12 samples $(66.66 \%)$ were ELISA positive using PPD as a coating antigen and decreased to be 11 and 11 positive samples $(61.11 \%)$ at $1 / 160$ serum dilution. At serum dilution of 1/320, 10 and 9 were ELISA positive on using ST-CF and PPD as a coating antigens respectively (Table 1).

\section{Discussion}

The intradermal tuberculin test has been the widest used diagnostic technique. It allows detection of cattle that have been exposed to $M$. bovis. However, in herds where control of T.B. is based on the identification and removal of reactors to this test, some animals in advanced stages of the disease and with open lesions don't show reactivity to tuberculin (anergic) and might remain in the herd, thus constituting a potential source of infection in susceptible cattle (DiazOtero et al., 2003). In the present study, 18 out of 300 tuberculin tested cattle, were found to be reactors with prevalence rate of $6.0 \%$. In the annual report of the general organization of veterinary service (GOVS, 1992) it was shown that the prevalence of bovine tuberculosis in cattle was high in certain Governorates such as Alexandria 6\%, Dakahlia 9.6\% and Behera $14.06 \%$ during 1992. The higher protein concentration of $M$. bovis culture filtrate antigen (ST-CF) revealed the effect of method used for protein concentration on the protein content at 2 weeks of growth. This is supported by the observation of Sorensen et al. (1995) who estimated the total protein content of CF of $M$. tuberculosis H37Rv and concluded that many factors affecting the total protein content such as the difference of method used in protein concentration (Freeze-dry system of ammonium sulphate precipitated protein) and the culture conditions. Protein content of ST-CF of M. bovis 
at $2^{\text {nd }}$ week of growth $(2.7 \mathrm{mg} / \mathrm{ml})$ explains the effect of age of the culture on the protein content of the mycobacterial culture filtrate antigen.

Enzyme linked immunosorbent assay (ELISA) is one of the important serological tests for diagnosis of bovine tuberculosis. ELISA technique was applied as a sensitive method for measurement of antibodies in sera of tuberculous animals (Engvall and Perlmann, 1972). The detection of antimycobacterial antibodies in the sera of infected cattle was evaluated by ELISA technique using ST-CF antigen of M. bovis and bovine PPD. Denaturation of PPD may occur due to the heating process leading to severe diminish of its sensitivity and specificity (Daniel and Janicki, 1978).

Regarding the comparison between results of tuberculin test and ELISA technique using bovine PPD and ST-CF at serum dilution $1 / 80$ as shown in (Table 1), 13 serum samples out of 18 tuberculin reactors, $(72.22 \%)$ were found positive for ELISA using bovine ST-CF and 12 samples were positive using PPD as coating antigens.

The result in the present study is in agreement with Lepper and Coner (1983) who stated that antibody response to $M$. bovis infection is certainly not uniform. This phenomenon was previously suggested in serological analysis by Hanna et al. (1992) who studied the humoral immune response to $M$. bovis infection in cattle and concluded that it was characterized by highly heterogeneous antigen recognition. Also these findings are supported by the results of Gupta and Ram (2000) who reported that the culture filtrate antigens are highly immunogenic for humoral response, being sensitive and specific when used for the diagnosis of bovine tuberculosis by ELISA technique. Also, Diaz-Otero et al. (2003) pointed out that ST-CF of $M$. bovis was more sensitive than bovine PPD.

The low titer of antibodies to mycobacterial antigens may be associated with heavy infection and antigens may be released into circulation and cause temporary suppression of antibody formation (Krambovitis et al., 1986).

\section{References}

Andersen, P.; Dorthf, A.; Leneljnngovis, T.; Jorgen, B. and Iver, H. (1991): Protein released from M. tuberculosis during growth. Infect. Immun., 59 (6): 1905-1910.

Cobner, A. (2003): Bovine tuberculosis; clinical update and on farm advice. In-practice, 25 (10): 606-613.

Cousins, D. V. and Florisson, N. (2005): A review of tests available for use in the diagnosis of tuberculosis in non bovine species. Rev. Sci. Tech. OIE., 24 (3): 1039-1059.
Daniel, T. M. and Janicki, B. W. (1978): Mycobacterial antigens: A review of their isolation, chemistry and immunological properties. Microbiol. Rev., pp. 113-119.

Diaz-Otero, F.; Banda-Ruiz, V.; Jaramillo-Meza, L; Arriaga-Diaz, C.; Gonzalez-Salazar, D. and EstradaChavez, C. (2003): Identification of Mycobacterium bovis infected cattle by immunological and molecular methods. Veterinaria-Mexico, 34 (1): 13-26.

Dimitri, R. A.; Soufy, H.; Amin; Gergis, S. M.; Awad, M. M. and Shawkat, M. E. (1990): Studies on serodiagnosis of bovine tuberculosis in Egypt. Egypt. Agric. Res. Rev., 68 (4): 853-863.

Engvall, E. and Perlmann, P. (1972): Enzyme-linked immunosorbent assay (ELISA). III. Quantitation of immunoglobulin in antigen coated tubes. J. Immunol., 109: 129-135.

GOVS (1992): General Organization for the Veterinary Services, Ministry of Agriculture, Egypt.

Gupta, V. K. and Ram, G. C. (2000): Fractionation and immunoreactivity of membrane associated proteins of $M$. bovis. Ind. J. Anim. Sci., 70 (10): 1015-1020.

Gupta, V. K.; Ram, G. C. and Bansal, M. P. (1998): Intracellular killing potential of macrophages activated with different $M$. bovis AN5 antigens.

Hall, M. R. and Thoen, C.O. (1985): Detection of mycobacterial antibodies in sera of $M$. bovis sensitized cattle using ELISA: Evaluation of assay parameters. Fed. Proc. $26^{\text {th }}$, USA 934-943.

Hanna, J.; Neill, S. D. and Brion, J. J. (1992): ELISA test for antibodies in experimental bovine tuberculosis. Vet. Microbiol., 31: 243-249.

Heilman, D. H. (1967): In vitro studies on polysaccharides of $M$. tuberculosis and delayed hypersensitivity. Am. Rev. Resp. Dis., 96 (2): 198-203.

Hewinson, G. (2000): Development of vaccines against bovine tuberculosis. $2^{\text {nd }}$ International Veterinary Vaccines and Diagnostics Conference, Oxford, 23-28July.

Krambovitis, E. (1986): Detection of antibodies to Mycobacterium tuberculosis plasma membrane antigen by enzyme linked immuno sorbent assay. J. Med. Microbiol., 21: $257-264$

Lawry, O. H; Rosebrough, N. J.; Farr, A. L. and Randall, R. J. (1951): Protein measurement with the Folin phenol reagent. J. Biol. Chem., 193: 265-275

Lepper, A.W. D. and Coner, L. A. (1983): Naturally occurring mycobacteriosis of animals in biology of mycobacteria. Vol 2 Academic pres London. pp. 478- 448.

Lyaschchenko, K. P; Poollock, J. M; Colangeil, R.; and Gennaro, M. L. (1998): Diversity of antigen recognition by serum antibodies in experimental bovine tuberculosis. Infect. Immun., 66 (11): 5344-5349

Narayanan, P. R.; Acharyulu, G. S.; Krishnamurthy, P. V.; Abdul-Rawoof and Tripathy, S. P. (1983): Evaluation of ELISA as a diagnostic test in pulmonary tuberculosis. Ind. J. Tuber., 30: 29-32.

Nassau, E.; Parsons, E. R. and Johnson, G. D. (1976): The detection of antibodies to Mycobacterium tuberculosis by microplates enzyme linked immunosorbent assay. Tuber., 57: 67-70.

Radostits, O. M.; Gay， C. D.; Blood， C. D. and Hinchcliff, K. W. (2000): Veterinary Medecine Textbook of the diseases of cattle, sheep, pigs, goats and horses; $9^{\text {th }}$ ed., Baillier, England.

Sorensen, A. L.; Nagai, S.; Hoven, G.; Anderson, P. and Anderson, B. (1995): Purification and characterization of low molecular mass $\mathrm{T}$ cell antigen secreted by $M$. tuberculosis. Infect. Immun., 63 (5): 1710- 1717 
Thom, M. L.; Hope, J. C.; McAulay, M.; VillarrealRamos, B.; Coffey, T. J.; Stephanes, S.; Vordermeier, H. M. and Howard, C. J. (2006): The effect of tuberculin testing on the development of cell-mediated immune responses during Mycobacterium bovis infection. Vet. Immunol. Immunopathol. 114:25-36.
Vordermeier, H. M.; Whelan, A.; Cockle, P. J.; Farrant, L.; Palmer, N. and Hewinson, R. G. (2001): Use of synthetic peptides derived from the antigens ESAT- 6 and CFP-10 for differential diagnosis of bovine tuberculosis in cattle. Clin. Diag. Lab. Immunol., 8 (3): 571- 578.

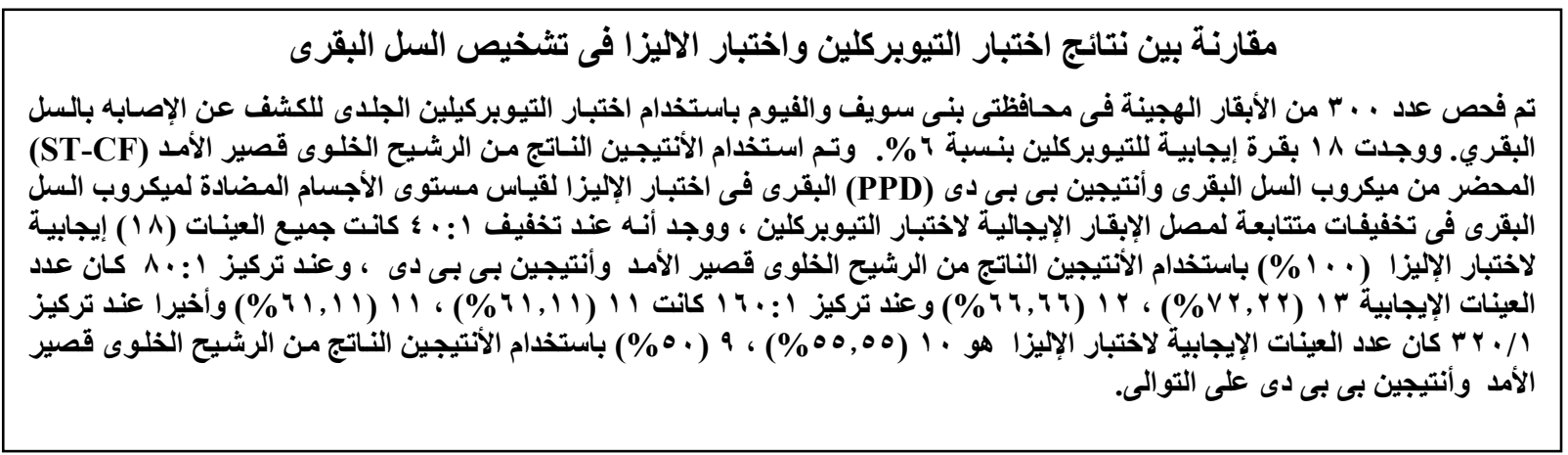

